\title{
Sirkadiese sekresiepatrone van $\beta$-endorfien en leusienenkefalien
}

\author{
E.H. de Wet* en J.M.C. Oosthuizen \\ Departement Fisiologie, Universiteit van die Oranje-Vrystaat, Bloemfontein 9301
}

H.C. Barnard

Departement Chemiese Patologie, Universiteit van die Oranje-Vrystaat, Bloemfontein 9301

H.G. Luus

Departement Farmakologie, Universiteit van die Oranje-Vrystaat, Bloemfontein, 9301

M.S. Bornman
Departement Urologie, Mediese Universiteit van Suider-Afrikid, Pretoria 0204

Ontvang 28 Augustus 1991; aanvaar 23 September 1991

\begin{abstract}
UITTREKSEL
$\beta$-endorfien en leusienenkefalien is neuropeptiede met kragtige opioiedaktiwiteit. In 'n studie om die sirkadiese sekresiepatrone van vermelde endogene opioiede te ondersoek, is bloedmonsters uurliks vir 'n periode van 24 uur van 12 normaalgesonde mans bekom. Plasmakonsentrasies van $\beta$-endorfien asook leusienenkefalien is volgens radio-immuun-essai-tegnieke gekwantifiseer. Piekkonsentrasies van $\beta$-endorfien kom gedurende die tydperk 08:00-09:00 voor, terwyl piekkonsentrasies van leusienenkefalien gedurende die tydperk 23:00-07:00 voorkom. Trogkonsentrasies van $\beta$-endorfien kom van 24:00-05:00 voor, terwyl trogkonsentrasies van leusienenkefalien van 09:00-12:00 voorkom. Tendense in die sirkadiese sekresiepatroon van $\beta$-endorfien simuleer die bekende sekresiepatroon van kortisol. 'n Moontlike verklaring vir die vergelykbare fenomeen is gesetel in die feit dat $\beta$-endorfien en kortikotropien uit 'n gemeenskaplike moedersubstans oorsprong het. Tendense in die sirkadiese sekresiepatroon van leusienenkefalien simuleer dié van melatonien opmerklik. Die rede hiervoor is onduidelik.
\end{abstract}

\section{ABSTRACT}

\section{Circadian secretion patterns of $\beta$-endorphin and leucine enkephalin}

$\beta$-endorphin and leucine enkephalin are neuropeptides with potent opioid activity. In a study to investigate the circadian secretion patterns of the above-mentioned, blood samples were collected hourly from 12 healthy males who were subjected to the experiment for 24 hours. Radioimmunoassays were used in the analysis of plasma samples for $\beta$-endorphin and leucine enkephalin. Peak concentrations of $\beta$-endorphin were demonstrated from 08:00-09:00, while peak concentrations of leucine enkephalin occured from 23:00-07:00. Trough concentrations of $\beta$-endorphin occurred from 24:00-05:00, while trough concentrations of leucine enkephalin were demonstrated from 09:00-12:00. The illustrated circadian secretion pattern for $\beta$ endorphin simulates the well-known circadian rhythm of cortisol. The answer to this may lie in the fact that $\beta$-endorphin and corticotropin stem from the same precursor. The illustrated circadian secretion pattern for leucine enkephalin simulates that of melatonin. The reason for this is unclear.

\section{INLEIDING}

$\beta$-endorfien, 'n 31-aminosuurpeptied met opioiedaktiwiteit, wat in struktuur met die karboksiterminaal van $\beta$-lipotropien ooreenstem, is 'n biosintese-eindproduk van intrasellulêre metabolisme van preproöpiomelanokortien.' Proöpiomelanokortien gee oorsprong aan opioïedpeptiede ( $\beta$-endorfien, $\beta$-lipotropien), maar ook aan nie-opioïedpeptiede (kortikotropien, melanotropien). ${ }^{\prime}$

Die aminosuurvolgordes van kortikotropien en $\beta$-lipotropien is opeenvolgend en word deur ' $n$ tripsiensensitiewe dipeptied (Lys-Arg) verbind.' $\beta$-lipotropien beskik oor geen opioiedaktiwiteit nie. ${ }^{1}$ Deur proteolitiese kliewing van gepaarde basiese aminosure in die $\beta$-lipotropienstruktuur word $\beta$-endorfien gevorm. ${ }^{2}$ Dit wil voorkom asof van al die endogene peptiede met opioïedaktiwiteit $\beta$-endorfien se farmakologiese profie' die naaste aan dié van morfien geleë is. ${ }^{3}$

Die sirkadiese sckresiepatroon van kortisol is welbekend. Kortisolsekresie nord deur sirkadiese fluktuasies in kortikotropiensekresie onderlê. ${ }^{+5}$ Toniese sekresie van kor-

*Outeur aan wie korrespondensie gerig kan word. tikotropien (uit kortikotrope selle van die menslike adenohipofise) word primêr deur pulsvrystelling van kortikoliberien uit die mediane eminensie van die hipotalamus gereguleer. ${ }^{6}$

Daar sou redelikerwys verwag kon word dat proöpiomelanokortienverwante peptiede ( $\beta$-endorfien, kortikotropien) op grond van 'n gemeenskaplike voorlopersubstans deur dieselfde beheermeganismes gereguleer word en ooreenstemmende sirkadiese sekresiepatrone vertoon. Enkele literatuurstudies onderskryf vermelde hipotese. ${ }^{7.8}$

Leusienenkefalien, ' $n$ pentapeptied met opioiedaktiwiteit, is 'n biosintese-eindproduk van intrasellulêre katabolisme van preproënkefalien asook preprodinorfien.9. 10. II, ${ }^{2}$ Die hoofbron van menslike plasmaleusienenkefalien is waarskynlik die byniermedulla. ${ }^{{ }^{3} \text { H }}$ Volgens die literatuur wil dit voorkom asof die enkefaliene ook sirkadiese fluktuasies in sekresie vertoon. ${ }^{15}, 16$

\section{DOEL VAN DIE STUDIE}

In die lig van ontoereikende inligting met betrekking tot "tydgekoppelde normaalwaardes" vir $\beta$-endorfien asook 
leusienenkefalien in die mens, is die hoofdoel van die studie die daarstel van konsentrasietydprofiele vir genoemde verbindings.

Die naasdoel van die studie is om die sekresiepatrone van vermelde endogene opiö̈ede (soos bevind in die studie), te vergelyk met/verantwoord teenoor bekende sekresiepatrone van fisiologies relevante hormone.

\section{MATERIAAL EN METODE}

Goedkeuring vir die eksperiment is deur die Etiese Komitee van die Fakulteit Geneeskunde aan die Universiteit van die Oranje-Vrystaat verleen.

12 manlike proefpersone is vir 'n periode van 24 uur in die eksperiment gebruik.

Proefpersone moes aan die volgende insluitingskriteria voldoen:

(a) Volwasse, normaalgesonde mans.

(b) Ouderdom 18-25 jaar.

(c) Liggaamsmassa $< \pm 10 \%$ van normale massa vir lengte (Metropolitan Tables, 1983).

(d) Nierokers.

Die volgende uitsluitingskriteria vir proefpersone was deurgaans van toepassing:

(a) Gereelde gebruik of misbruik van alkohol.

(b) Gebruik van farmaseutiese preparate (insluitend "oordie-toonbank-geneesmiddels") tydens die voorafgaande 14 dae.

(c) Geskiedenis/aanwesigheid van enige akute/chroniese/ fisiese/psigiese siektetoestand.

Omgewingsfaktore is streng tydens die eksperiment gekontroleer (byvoorbeeld lig-/donkerblootstelling). Proefpersone is blootgestel aan kamerbeligting van \pm 350 Lux. Gereelde voginname asook maaltye is gestandaardiseer. Proefpersone is aan streng bedrus onderwerp, dog is toegelaat om op gespesifiseerde tye, vir gespesifiseerde tydperke op te staan.

Veneuse bloed vir die bepaling van plasma- $\beta$-endorfienasook -leusienenkefalienkonsentrasies is uurliks vir die duur van die studie van elke proefpersoon deur 'n inblywende intraveneuse kannule bekom in verkoelde $\left(4^{\circ} \mathrm{C}\right)$, silikoonbedekte vakuumbuise met vooraf bygevoegde EDTA $(1 \mathrm{mg} / \mathrm{ml})$ as antistolmiddel, asook L-triptofaanhidroksamaat $(0,08 \mathrm{mg} / \mathrm{ml})$ as ensieminhibeerder. ${ }^{17 .}{ }^{18}, 19$

Die bloedmonsters is direk na insameling in ys geplaas en tot $4^{\circ} \mathrm{C}$ afgekoel. Die bloedmonsters is daarna by $4^{\circ} \mathrm{C}$ vir 10 minute teen 4000 o.p.m. gesentrifugeer. Plasma wat uit die bloedmonsters bekom is, is na skoon polipropileenbuise oorgedra. Vir bewaringsdoeleindes is die plasmamonsters met $100 \mu \mathrm{l}$ soutsuur (1 Normaal) per milliliter plasma aangesuur en by $-20^{\circ} \mathrm{C}$ geberg. ${ }^{17 .}{ }^{18}, 19$

Nadat die plasma ontdooi is, is opioïedpeptiede geëkstraheer met behulp van 'n omkeerfase-vloeistofsilaangebonde faseskeier (Sep-Pak C18, Waters Associates, USA) en metanol as elueermiddel. ${ }^{17,18,19}$ Plasmakonsentrasies van $\beta$-endorfien asook leusienenkefalien is hierna volgens erkende biologiese tegnieke (R.I.A.) gekwantifiseer. ${ }^{20}$ Ten einde interessaivariasie te voorkom, is alle monsters van elke proefpersoon in dieselfde essai gekwantifiseer. Die intraessai-koëffisiënt van variasie was $<5 \%$.

Bykomstig is veneuse bloed vir die bepaling van serumkortisolkonsentrasies om 16:00, 24:00, 04:00 asook om 08:00 volgens ' $n$ aanvaarde materiaalinsamelingstegniek van vermelde proefpersone bekom. Serumkortisolkonsentrasies is volgens 'n erkende biologiese tegniek (Coat-A-Count ${ }^{k}$, Diagnostic Products Corporation, USA) gekwantifiseer.

\section{STATISTIESE ONTLEDING}

Die rekenkundige gemiddelde \pm standaardafwyking is vir proefresultaatwaardes bereken. Waar vergelykende statistiek van toepassing was, is Student se t-toets vir gepaarde data aangewend. Daar is deurgaans van 95\%-vertrouensintervalle gebruik gemaak om veranderlikes te vergelyk.

\section{RESULTATE}

Piekkonsentrasies van $\beta$-endorfien kom gedurende die tydperk 08:00-09:00 voor. Trogvlakke van $\beta$-endorfien kom tussen 24:00 en 05:00 voor. Die hoogste gemiddelde plasma$\beta$-endorfienkonsentrasie is statisties met die laagste konsentrasie vergelyk. Die gemiddelde plasma- $\beta$ endorfienkonsentrasie om 09:00 is $167,65 \%$ (95\%-vertrouensinterval: $128,73 \% ; 206,79 \%$ ) hoër as dié van 02:00 (figuur 1).

Piekkonsentrasies van leusienenkefalien kom gedurende die tydperk 23:00-07:00 voor. Trogvlakke van leusienenkefalien kom tussen 09:00 en 12:00 voor. Die hoogste gemiddelde plasmaleusienenkefalienkonsentrasie is statisties met die laagste konsentrasie vergelyk. Die gemiddelde plasmaleusienenkefalienkonsentrasie om 02:00 is

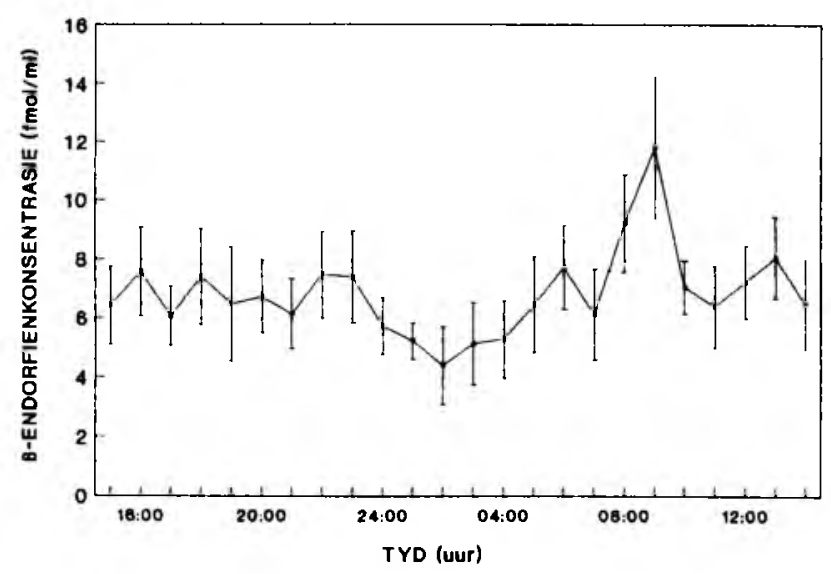

FIGUUR 1: Die gemiddelde plasma-ß-endorfienkonsentrasies soos uurliks tydens 'n 24-uurperiode in twaalf normaalgesonde mans bevind.

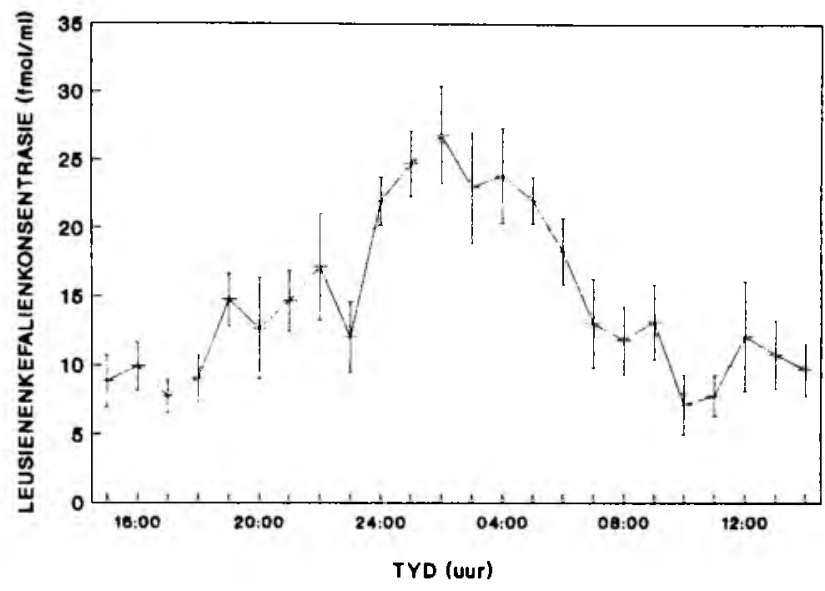

FIGUUR 2: Die gemiddelde plasmaleusienenkefalienkonsentrasies soos uurliks tydens in 24-uurperiode in twaalf normaalgesonde mans bevind. 
$275,45 \%$ (95\%-vertrouensinterval: $238,49 \% ; 312,41 \%$ ) hoër as dié van 10:00 (figuur 2).

Die hoogste (08:00) gemiddelde serumkortisolkonsentrasie is statisties met die laagste (24:00) konsentrasie vergelyk. Die gemiddelde serumkortisolkonsentrasie om 08:00 is $269,43 \%$ (95\%-vertrouensinterval: $227,85 \% ; 311,09 \%$ ) hoër as dié van 24:00. Geen hoër waarde as dié van 08:00 is op enige ander tyd (24:00/16:00/04:00) aangetoon nie. Geen waarde was selfs $>75 \%$ van die 08:00-waarde nie (figuur 3).

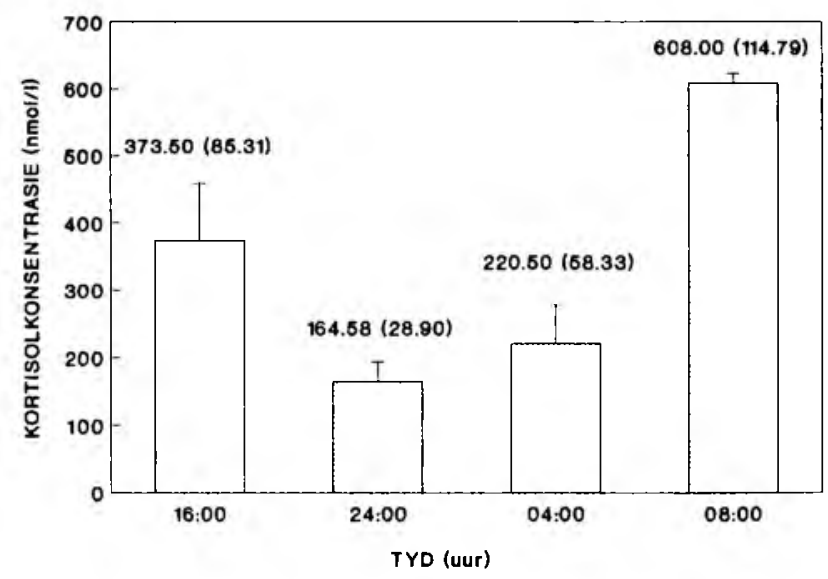

FIGUUR 3: Die gemiddelde serumkortisolkonsentrasies soos periodiek tydens ' $n$ 24-uurperiode in twaalf normaalgesonde mans bevind.
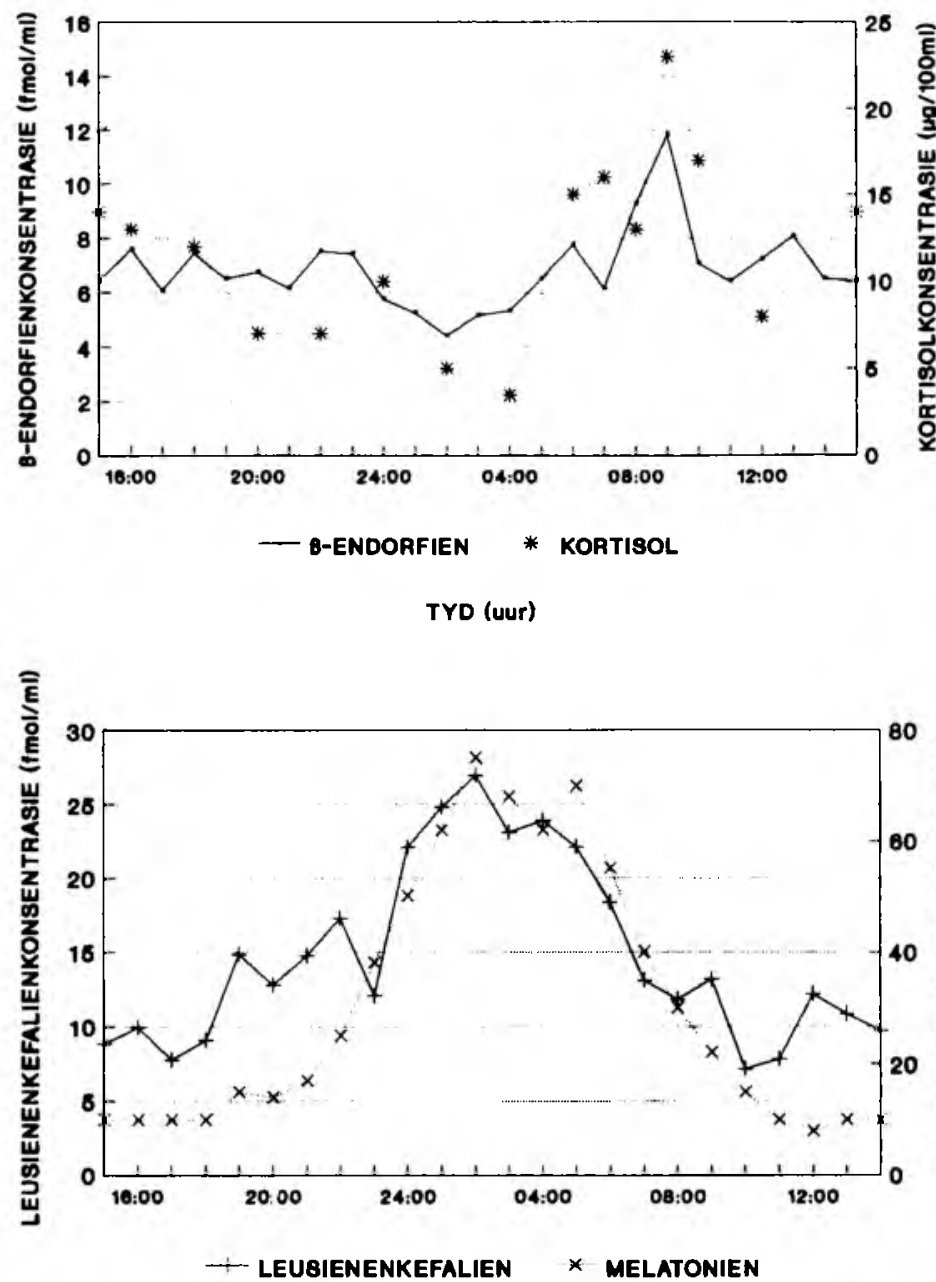

\section{BESPREKING VAN RESULTATE}

Literatuurstudies toon aan dat kortikotropien, kortisol asook $\beta$-endorfien ooreenstemmende sirkadiese sekresiepatrone in volwassenes vertoon. ${ }^{7.8}$

Petraglia en medewerkers het $\beta$-endorfienkonsentrasies van $6,3 \pm 0,5 \mathrm{fmol} / \mathrm{ml}$ en $3,7 \pm 0,6 \mathrm{fmol} / \mathrm{ml}$ onderskeidelik om 08:00 en 20:00 genotuleer. ${ }^{7}$ Vergelykbare fluktuasies is in kortisolkonsentrasies aangetoon. ${ }^{7}$ Dent en medewerkers het aangetoon dat die nadir in $\beta$-endorfienkonsentrasies gedurende die nag (22:00-03:30) voorkom, terwyl die piek in $\beta$-endorfienkonsentrasies soggens (04:00-10:00) voorkom. ${ }^{8}$

Volgens die resultate van die studie wil dit voorkom asof $\beta$-endorfien wel 'n sirkadiese sekresiepatroon vergelykbaar met dié van kortisol vertoon (figuur 4). Dit strook met resultate van Petraglia en Dent. ${ }^{7.8}$

Sirkadiese fluktuasies in metionienenkefalienkonsentrasies is in rothipotalamus gerapporteer met die hoogste weefselkonsentrasies om ongeveer middernag en die laagste tussen 09:30 en 10:30. ${ }^{16}$ Vergelykbare konsentrasieveranderinge van enkefaliene is in die globus pallidus van die rot gerapporteer. ${ }^{15}$ In dié studie is 'n $100 \%$ toename in enkefaliensekresie tussen 14:00 en 22:00 aangetoon. In vermelde studies is die akrofase van die sirkadiese enkefaliensekresie in verband gebring met dié van luliberien asook die resiproke tendense in testosteroon- en gamma-aminobottersuursekresie (GABA). ${ }^{15}{ }^{16}$

Dit is bekend dat melatonien, prolaktien en somatotropien onder basale omstandighede, piekkonsentrasies gedurende die nag bereik. ${ }^{21,22,23,24}$ Die sekresiepatroon van somatotropien is egter slaapgeassosieerd en verteen

FIGUUR 4: 'n Vergelyking tussen die sirkadiese sekresiepatroon van $\beta$-endorfien (bevind) en kortisol (bekend). ${ }^{26}$
FIGUUR 5: 'n Vergelyking tussen die sirkadiese sekresiepatroon van leusienenkefalien (bevind) en melatonien (bekend). ${ }^{21}$ 
woordig dus nie 'n egte sirkadiese sekresiepatroon nie. ${ }^{24}$ Die sirkadiese sekresiepatroon van prolaktien in die mens is fluktuerend en labiel. ${ }^{23}$ Dit word deur verskeie fisiologiese faktore en patologiese toestande, asook geneesmiddels (bromokriptien, metisergied) gemoduleer. ${ }^{23}$ Volgens die literatuur is dit bekend dat die sirkadiese sekresiepatroon van prolaktien ook slaapgeassosieerd is en dat 'n toename in sekresie gedurende nie-REM-slaapperiodes (01:00-05:00) voorkom. ${ }^{23 .}{ }^{25}$ Dit is bekend dat die akrofase van die sirkadiese sekresiepatroon van melatonien ('n potente dopamienantagonis) na middernag (02:00-05:00) voorkom. ${ }^{21,22}$

Bovermelde tendense in die sirkadiese sekresiepatroon van leusienenkefalien simuleer ooglopend die bekende sekresiepatroon van melatonien (figuur 5 ).

\section{GEVOLGTREKKING}

Tendense in die sirkadiese sekresiepatroon van $\beta$-endorfien simuleer die bekende sekresiepatroon van kortisol. 'n Moontlike verklaring vir die vergelykbare fenomeen is gesetel in die feit dat $\beta$-endorfien en kortikotropien uit 'n gemeenskaplike voorlopersubstans (preproöpiomelanokortien) oorsprong het. Die sirkadiese sekresiepatroon wat kortisol vertoon, word deur sirkadiese fluktuasies in kortikotropiensekresie onderlê.

Die rede vir die onmiskenbare ooreenkoms tussen die sirkadiese sekresiepatrone van leusienenkefalien en melatonien is onduidelik.

\section{LITERATUURVERWYSINGS}

1. Nakanishi, S. et al. (1979). Nucleotide sequence of cloned cDNA for bovine cortico- $\beta$-lipotropin precursor, Nature, 278, 423-427.

2. Burbach, J.P.H. (1984). Action of proteolytic enzymes on lipotropins and endorphins: Biosynthesis, biotransformation and fate, Pharmacol Ther, 24, 321-354.

3. Way, W.L. \& Way, E.L. (1989). In Basic and Clinical Pharmacology, Katzung, B.G. ed. (Appleton and Lange, Los Altos, California) p. 369.

4. Granner, D.K. (1990). In Harper's Biochemistry, Murray, R.K. et al. (Appleton and Lange, Los Altos, California) p. 499-510.

5. Goldfien, A. (1989). In Basic and Clinical Pharmacology, Katzung, B.G. ed. (Appleton and Lange, Los Altos, California) p. 479-492.

6. Granner, D.K. (1990). In Harper's Biochemistry, Murray, R.K. et al. (Appleton and Lange, Los Altos, California) p. 478-486.

7. Petraglia, F. et al. (1983). Simultaneous circadian variations of plasma
ACTH, beta-lipotropin, beta-endorphin and cortisol, Horm Res, 17 , 147-152.

8. Dent. R.R.M. et al. (1981). Diurnal rhythm of plasma immunoreactive beta-endorphin and its relationship to sleep stages and plasma rhythms of cortisol and prolactin, $J$ Clin Endocrinol Merab, 52. 942-947.

9. Hughes, J. (1975). Isolation of an endogenous compound from the brain with pharmacological properties similar to morphine, Broin Res, 88, 295-308.

10. Hughes, J. et al. (1975). Identification of two related pentapeptides from the brain with potent opiate agonist activity, Nature, 258, 577-579.

11. Noda, M. et al. (1982). Cloning and sequence analysis of cDNA for bovine adrenal preproenkephalin, Nature, 295, 202-206.

12. Nyberg, F., Nordström, K. \& Terenius, L. (1985). Biochem Biophys Res Comm. 131, 1069-1074

13. Lewis, R.V. et al. (1980). An about 50,000-dalton protein in adrenal medulla - a common precursor of met- and leu-enkephalin, Science 208, 1459-1461

14. Millan, M.J. \& Herz, A. (1985). The endocrinology of the opioids, Int Rev Neurobiol, 26, 1-83.

15. Bayon, A. \& Anton, B. (1986). Diurnal rhythm of the in vivo release of enkephalin from the globus pallidus of the rat. Regulatory Pepides, 15, 63-70.

16. Kumar, M.S.A. et al. (1982). Diurnal fluctuation in methionineenkephalin levels in the hypothalamus and preoptic area of the male rat: effects of pinealectomy, Neuroendocrinology, 35, 28-31.

17. Lotti, M. et al. (1986). Radioimmunoassay of leucine-enkephalin, J Nucl Med Allied Sci, 30(1), 5t-55.

18. Hong, J-S, Yoshikawa, K. \& Hendren, R.W. (1983). Measurement of $\beta$-endorphin and enkephalins in biological tissues and fluids. Methods Enzymol, 103, 547-564.

19. Cahill, C.A., Matthews, J.D. \& Akil, H. (1983). Human plasma $\beta$ endorphin-like peptides: A rapid, high recovery extraction technique and validation of radioimmunoassay, $J$ Clin Endocrinol Merab, 56(5), 992-997.

20. De Wet, E.H. (1991). Normale en gewysigde sirkadiese sekresiepatrone van endogene opioiede in die mens, MD-proefskrif, Universiteit van die Oranje-Vrystaat. Bloemfontein, p. 113-132.

21. Arendt, J. et al. (1982). 24-Hour profiles of melatonin, cortisol, insulin, C-peptide and GIP following a meal and subsequent fasting. Clin Endocrinol, 16, 89-95.

22. Coetzee, J.A., Theron, J.J. \& Van der Merwe, C.A. (1989). Consecutive melatonin circadian rhythms in normal volunteers, $S$ Afr Med J, 75, 163-165.

23. Robyn, C. et al. (1977). In Prolactin and Human Reproduction, Crosignani P.G. and Robyn, C. eds. (Academic Press, New York) p. 71-96.

24. Porter J.C. (1974). In Biorhythms and Human Reproduction, Ferin. M. et al. eds. (John Wiley and Sons, New York) p. 607-650.

25. Kant, G.J., Mougey, E.H. \& Meyerhoff, J.L. (1986). Diurnal variation in neuroendocrine response to stress in rats: Plasma ACTH, $\beta$ endorphin, $\beta-L P H$, corticosterone, prolactin and pituitary cyclic AMP responses, Neuroendocrinology, 43, 383-390.

26. Krieger, D.T. et al. (1971). Characterization of the normal temporal pattern of plasma corticosteroid levels, J Clin Endocrinol Metab, $32,266-284$ 